\title{
THE RELATIONSHIP BETWEEN WNT (WINGLESS/INT) PATHWAYS REACTIVE OXYGEN SPECIES (ROS) AND CANCER
}

\author{
Fitriannisa F. Zubaidi \\ Fakultas Kedokteran Universitas Islam Al-Azhar \\ J1. Unizar No.20 Turida Mataram
}

\begin{abstract}
Reactive oxygen species has been known to play a role in the formation of cancer and determination of cellular death. Less known, however, is its more recently studied role in regulating cellular physiologic functions. The mechanism of how ROS switches between these roles involves detailed interactions with different pathways. The Wnt pathway, specifically the canonical Wnt/ $\beta$-catenin pathway, seems to be one that has this role switching effect, depending on the amount of ROS present in the cellular microenvirent. This review aims to revisit the regulation of ROS levels, their relationship to cancer, and how the Wnt pathways influence the effect of ROS.
\end{abstract}

Key Words : ROS, Wnt, $\beta$-catenin, cancer, nucleoredoxin (Nrx), TCF/LEF, Fox.

\section{INTRODUCTION}

Reactive oxygen species (ROS) are chemically reactive oxygen-containing molecules that play a crucial role in the biology of living organisms. It has previously been shown that excessive levels of ROS can cause cellular damage, as well as lead to ageing and cancer (Serrano \& Blasco, 2007). However, recent studies have recognized their role as physiologic signalling molecules that drive cell function when maintained at a balanced low level, and their dysregulation contributing to various pathologies (Katsuyama, Matsuno, \& Yabe-Nishimura, 2012; Zhou, Shao, \& Spitz, 2014). One group of molecules that seem to have significant effect on this balance is the diverse family of the Wnt signalling glycoproteins (R. Nusse \& Clevers, 2017).

It has been proposed that one of the three known Wnt signalling pathways, the
Wnt/ $\beta$-catenin pathway, plays a role in directing cell response to oxidative stress. Under normal physiological conditions, Wnt ligands stimulates a cascade of signalling events that regulate cellular proliferation with a unique feature of being responsible for directional instructions essential for growth and development (R. Nusse \& Clevers, 2017). $\beta$-catenin nuclear localization is a result of canonical Wnt signalling in the 'on' state, where it acts as a cofactor for the transcriptional activity of $\mathrm{T}$-cell factor (TCF) and Lymphoid enhancer-binding factor (LEF). However, recent evidence suggest that as well as its traditional role as a downstream effector, $\beta$-catenin may also bind to several other transcription molecules, for example the O-class of Forkhead box (FoxO) transcription factors, whose target genes are mainly related to the cellular responseof oxidative stress(Hoogeboom \& 
Burgering, 2009). This occurred in the presence of ROS, suggesting the pivotal role of the Wnt/ $\beta$-catenin pathway in determining the cell response to oxidative stress.

\section{Reactive Oxygen Species}

ROS regulation: generation and elimination

ROS are formed as the result of aerobic metabolism, for example in the mitochondria through the electron transport chain, when $\mathrm{O}_{2}$ is not fully reduced to water. This partial reduction may result in free radical molecules, such as $\mathrm{O}_{2}^{-}$(superoxide), which is readily converted into other forms of ROS, including ${ }^{*} \mathrm{HO}$ (hydroxyl radicals); these moleculeshave unpaired electrons and will oxidize other molecules, resulting in a cascade of instability(Lam, Huang, \& Brumell, 2010; Pande et al., 2015). Nonradical ROS may also be produced, for example $\mathrm{H}_{2} \mathrm{O}_{2}$ (hydrogen peroxide), where all electrons are paired, but the molecule is still not in a preferred stable state, and thus can easily transform into hydroxyl radicalsthrough the Fenton reaction or into $\mathrm{HOCl}$ by the enzyme myeloperoxidase, although it may also be fully reduced into water by catalase(Lam et al., 2010). In addition, ROS may also be produced by the transfer of electrons from NADPH to $\mathrm{O}_{2}$ when the former is oxidized by the NADPH oxidase (NOX) enzymes located on cell membranes.

ROS generation by NOXs was originally discovered as a mechanism of cellular defence where NOX-derived ROS would kill pathogens engulfed by phagocytes(Lam et al., 2010). It is now understood that ROS generated by NOX also mediates signalling in numerous cell types, where it is proposed to also play a role in facilitating the survival of cancer cells (Zhou et al., 2014). Other than these two main sources, ROS may also be generated from several other sources, including peroxisomes (Antonenkov, Grunau, Ohlmeier, \& Hiltunen, 2010), metabolic activity of cytochrome P450 (Prasad, Mah, Lewis, \& Plettner, 2013), and immune cells in chronic inflammation (Nathan \& CunninghamBussel, 2013).

To ensure the maintenance of low level ROS in normal cells and theprotectionof the deteriorative effects of high levels of ROS, ROS generation is compensated by elimination pathways, which rely on dietary antioxidants, such as vitamins $\mathrm{C}$ and $\mathrm{E}$, reducing-molecules, and antioxidant enzymes(Zhou et al., 2014). Superoxide dismutase (SOD) is an antioxidant enzyme that converts the highly unstable superoxide into the nonradical $\mathrm{ROS}, \mathrm{H}_{2} \mathrm{O}_{2}$. Three classes have been characterized: the copper-zinc SOD1 (CuZnSOD) found in cytosol, as well as 
the outer mothochondrial membrane (OMM), manganese-containing SOD2 (MnSOD)in mitochondria, and the extracellular SOD3 (ecSOD) which also contains copper and zinc (Che, Wang, Li, Wang, \& Zheng, 2016). Catalase is another antioxidant enzyme, contained within peroxisomes, which reduces $\mathrm{H}_{2} \mathrm{O}_{2}$ into water and $\mathrm{O}_{2}$ (Zhou et al., 2014).

The reducing molecule glutathione is involved in another mechanism of ROS elimination where its reduced form (GSH) can be oxidized at its cysteine residue by ROS to form GSSG (two glutathione molecules adjoined by a disulphide bond) (Zhou et al., 2014). Thioredoxin (Trx) is another reducing molecule crucial for redox regulation, where Trx 1 can be found in the cytosol while $\operatorname{Trx} 2$ in the mitochondria (Lee, Kim, \& Lee, 2013). Nucleoredoxin, a member of the thioredoxin family originally found in the nucleus, was reported as a regulator of the $\mathrm{Wnt} / \beta$ catenin pathway (Funato, Michiue, Asashima, \& Miki, 2006).

\section{ROS Regulation and Cancer}

Studies have suggested the dual role of ROS in cancer formation and progression, where it promotes cell transformation towards a cancerous nature on one hand; while on the other hand, it may also trigger cancer cell death(Reczek \& Chandel, 2017). Cancer cells have an altered metabolic state where they not only produce more ROS, but also adapt to it by up-regulating their antioxidant systems, resulting in overactive cellular signalling, driving the cell survival and proliferation characteristics of cancerous cells (Moloney \& Cotter, 2017). For example, although a decrease of MnSOD activity was consistently found in the initial stages of many cancerous cells, recent evidence suggest that this may not depict the whole picture, as MnSOD is found to be up-regulated as the cancer develops (Dhar \& St Clair, 2012). Similarly, during cancer progression, catalase has been found to be responsible for cancer cell resistance to apoptosis through the $\mathrm{HOCl}$ pathway, which is dependent on $\mathrm{H}_{2} \mathrm{O}_{2}$ (Bauer, 2012; Scheit \& Bauer, 2015). This shows the complex and stagedependent regulation of carcinogenesis by ROS, where, the over accumulation of ROS, that would have caused cell death in normal cells, is neutralized by the parallel increase in ROS scavenging.

\section{Wnt Signalling Pathways}

Over 40 years ago, the wingless gene was reported to regulate the development pattern of Drosophila melanogaster (Zhan, Rindtorff, \& Boutros, 2017). R. Nusse and Varmus (1982) then discovered the mammalian homolog, Int-1, as an oncogenic provirus 
found in mouse mammary tumours. The nomenclature was later adjusted as the Wnt (Wingless/Int) family where Int-1 became Wnt-1 (R Nusse et al., 1991). Three Wnt signalling pathways have been characterised, the $\beta$-catenin-dependent canonical Wnt signalling, and the two non-canonical pathways, planar cell polarity (PCP) and calcium-dependent signalling, all of which are initiated by the interaction between the Wnt ligand and receptor (Zhan et al., 2017).

Wnt signalling is highly conserved across species and is one of the pathways involved in the development stages of organisms with the speciality of giving a direction for the growth (R. Nusse \& Clevers, 2017). It also maintains the properties of stem cells in adult tissues(Zhan et al., 2017). Correlations between aberrant Wnt signallingand many types of cancer has thus been observed (Clements et al., 2002; Dahmen et al., 2001; Nishisho et al., 1991; Pohl et al., 2017; Satoh et al., 2000; Segditsas \& Tomlinson, 2006).

\section{Wnt/B-Catenin Pathway}

The canonical Wnt pathway regulates the level of cytosolic $\beta$-catenin, where in the absence of a Wnt signal (the "off" state), the $\beta$-catenin destruction complex is intact, resulting in a low level of $\beta$-catenin. The $\beta$-catenin destruction complex is comprised of Axin (which acts as a scaffold protein), adenomatous polyposis coli (APC; whose mutation is related to colorectal cancer), GSK3 $\beta$ (which phosphorylates $\beta$-catenin), CK1 $\alpha$, and $\beta \mathrm{TrCP}$, which ubiquitinates $\beta$-catenin, taggingit for degradation by proteasome (Latres, Chiaur, \& Pagano, 1999). In contrast, when a Wnt ligand binds to the receptor complex (the "on" state), the destruction complex is disrupted, resulting in a stabilized high level of cytosolic $\beta$-catenin, which leads to an increased nuclear localization (Zhan et al., 2017). In the nucleus, $\beta$-catenin acts as a cofactor for the transcription factors TCF and LEF, replacing the repressive complex of transducing-like enhancer (TLE/Groucho) protein (MacDonald, Tamai, \& He, 2009). This results in the transcription of the Wnt target genes and the initiation of various cellular processes (Clevers, 2006; MacDonald et al., 2009).

The signalling is activated when a Wnt ligand binds to the receptor complex of Frizzled (Fzd) receptor and Lipoprotein receptor-related protein-5 (LRP-5) or LRP-6 co-receptor. Glycogen synthase kinase-3 $\beta$ (GSK3 $\beta$ ) and casein kinase- $1 \alpha(\mathrm{CK} 1 \alpha)$ are then recruited and phosphorylate LRP-5/6 which then recruits Dishevelled (Dvl) proteins to the plasma membrane, where they become polymerized and active (Metcalfe, Mendoza-Topaz, Mieszczanek, \& Bienz, 2010). Dvl then inactivates the $\beta$-catenin 
destruction complex, thus allowing $\beta$ catenin accumulation in the cytosol and translocation to the nucleus.

\section{Planar Cell Polarity Pathway}

The planar cell polarity (PCP) pathway is essential for the organization of tissues by coordinating the polarity of adjacent cells in a two dimensional sheet of cells amongst other cellular processes related to the orientation of cellular growth ( $\mathrm{Li}$ et al., 2011).Similar to the canonical Wnt signalling, non-canonical Wnt ligandsbind to the receptor complex of Fzd receptor and recruit Dvl to the plasma membrane (De Marco et al., 2014). Research by Qi et al. (2017) suggests that Dvl, particularly its $\mathrm{C}$ terminus, controls the activation of both pathways. In the PCP pathway, through interaction with Dvl-associated activator of morphogenesis 1 (Daam1), Dvl then binds to Rho, leading to its activation and Rho-associated protein kinase (ROCK) mediated signalling, and cytoskeleton rearrangement (Pataki, Couchman, \& Brabek, 2015). Dvl also binds to Rac 1 and activate c-Jun-N-terminal kinase (JNK) leading to the transcription of PCP pathway target genes(Pataki et al., 2015).

\section{Wnt/Calcium Pathway}

In $\mathrm{Wnt} / \mathrm{Ca}^{2+}$ signalling, the binding of a Wnt ligand leads to the activation of phospholipase $\mathrm{C}$, followed by an influx of
$\mathrm{Ca}^{2+}$ into the cytoplasm(Wang, 2009). This then activates downstream effectors including protein kinase $\mathrm{C}$ (PKC) and and Cam kinase $\left(\mathrm{Ca}^{2+} /\right.$ calmodulin-dependent kinase (CamK) (Kikuchi, Yamamoto, Sato, \& Matsumoto, 2012). This results in many cellular effects, including inhibition of $\mathrm{Wnt} / \beta$-catenin signalling, alteration to cell adhesion, and cell differentiation (Miller \& McCrea, 2010). New modulators of the pathway are gradually being recognized, for example the Calpain2 protein that is activated by Wnt5a, which takes part in regulating mesoderm migration and mesoderm and neural convergent extension (Zanardelli, Christodoulou, \& Skourides, 2013). It is also thought to modulate the crosstalk between the $\mathrm{Wnt} / \mathrm{Ca}^{2+}$ and $\mathrm{Wnt} / \mathrm{PCP}$ pathways (Zanardelli et al., 2013).

\section{ROS-Wnt Pathway Interaction}

ROS Enhances Wnt/ $\beta$-Catenin Signalling Through Nrx

Nucleoredoxin (Nrx), is a member of the thioredoxin family and is predominately found in the nucleus. Funatoet al. identified it as a regulator of Wnt signalling for its role in disrupting the $\beta$-catenin cytoplasmic destruction complex (Funato et al., 2006). In this study, they found that Nrx interacts with cytoplasmic Dvl, preventing its recruitment to the plasma membrane via interaction with the cytoplasmic portion 
of the transmembrane Frizzled receptor. This Nrx-bound Dvl cannot be recruited and disruption the $\beta$-catenin destruction complex occurs, thus leading to the eventual degradation of $\beta$-catenin. Furthermore, Funato et al. (2006)demonstrated that this Nrx-Dvl binding is interrupted by ROS, in this case $\mathrm{H}_{2} \mathrm{O}_{2}$, stabilizing the cytoplasmic $\beta$ catenin concentration, and increasing downstream TCF/LEF transcription factor activity. They concluded that ROS had positive effects on $\mathrm{Wnt} / \beta$-catenin signalling. In addition to this, a subsequent study by Funato et al. (2010)reported that the binding of Nrx to Dvl not only prevents Dvl activation in the Wnt/ $\beta$-catenin pathway, but also prevented it from being degraded by Kelch-like 12 (KLHL 12). These studies highlight the importance of the antioxidant molecule, Nrx, in the ROSmediated regulation of $\mathrm{Wnt} / \beta$-catenin signalling.

Kajla et al. (2012)conducted a study that further enhances the knowledge on this matter, where they found that Wnt ligand-receptor interaction itself induces ROS production by NADPH oxidase 1 (Nox1) that causes the Nrx-Dvl dissociation. This process happens initially through Wnt activation of Src (a tyrosine kinase), followed by Src phosphorylation of Vav2 (a Rac guaninenucleotide exchange factor), which in turn induces the activation of Rac1 (a GTPase from the Rho superfamily) through the switch of bound molecule GDP (released) to GTP (captured) (Kajla et al., 2012). Rac1 then transduces the signal to NOX1 , causing ROS production in the form of superoxide, which is both time and dose dependent(Kajla et al., 2012). Nox1derived ROS oxidises Nrx, causing its disassociation from Dvl, which eventuates with the disruption of $\beta$ catenin destruction complex and activation of the $\mathrm{Wnt} / \beta$-catenin signalling pathway (Kajla et al., 2012).

Consistent with the findings of Funatoet al., Kim et al. have also demonstrated ROS-induced activation of the $\mathrm{Wnt} / \beta$-catenin pathway (Kim, Kim, Na, \& Surh, 2010). Human breast epithelial cells, from the MCF-10A line, treated with tumour necrosis factor- $\alpha$ (TNF- $\alpha$, also referred to as TNF, a proinflammatory cytokine believed to be the link between inflammation and tumour formation) resulted in an increased expression of urokinase-type plasminogen activator (uPA, a serine protease involved in extracellular matrix degradation in cancer) by increasing nuclear localization of $\beta$-catenin and increasing TCF-4 binding to DNA, both indicating activation of Wnt signalling, which was mediated by an increase of intracellular ROS, possibly through the mechanism 
described by Funato et al (Kim et al., 2010).

In contrast with these findings, studies have reported results where treatment with $\mathrm{H}_{2} \mathrm{O}_{2}$ causes a decreased $\mathrm{Wnt} / \beta$-catenin signalling, mainly due to the dual roles of $\beta$-catenin, where it binds to and increases the transcription activity of not only TCF/LEF transcription factors, but also Forkhead box-O (FoxO), in which $\beta$-catenin seems to have binding preferences with the latter, resulting in shift from the traditional TCF/LEF transcription activity (Almeida, Han, Martin-Millan, O'Brien, \& Manolagas, 2007; Dong et al., 2013; Essers et al., 2005; Hoogeboom et al., 2008). Another mechanism reported to lead to the negative effects of ROS on Wnt $/ \beta$-catenin signalling pathway is the direct downregulation of $\beta$-catenin by ROS by activation of GSK $3 \beta$ (Shin, Chin, Lee, \& Kim, 2006; Shin et al., 2004).

ROS Decreases Wnt Target Gene Expressions Due To The Diversion Of BCatenin Binding, From TCF/LEF to FoxO Transcription Factors

FOXO is known to regulate the expression of genes required for cellular response to oxidative stress such as catalase and MnSOD (Hoogeboom \& Burgering, 2009). However, their activity, in turn, is regulated by ROS. This regulation was reported by Essers et al.
(2005) from studies conducted on various cell lines and in vivo on Caenorhabditiselegans, where they demonstrated the binding of $\beta$-catenin to FOXO, which is found to be enhanced by $\mathrm{H}_{2} \mathrm{O}_{2}$ stimulation. Reinforcing these results, Almeida et al. (2007),studied mesenchymal and osteoblastic cell lines and reported an interactionbetween FOXO and $\beta$-catenin which was enhanced by $\mathrm{H}_{2} \mathrm{O}_{2}$, followed by an increase in FOXO transcriptional activity. On the other hand, contrary to the effects on FOXO, the transcriptional activity of TCF is supressed in the presence of an increasing dose of $\mathrm{H}_{2} \mathrm{O}_{2}$ and that this effect occurs downstream of $\beta$ catenin(Almeida et al., 2007). Furthermore, they also reported that this suppression of TCF activity in the presence of $\mathrm{H} 2 \mathrm{O} 2$ was rescued by overexpressing $\beta$-catenin, suggesting that this suppressive effect is due to a diversion of $\beta$-catenin binding preference from TCF to FOXO within a limited pool of $\beta$-catenin(Almeida et al., 2007). Similar results of this competitive nature between TCF and FoxO transcription factors were reported by Hoogeboom et al. (2008) from experiments on DL23 and DLD1 human colon carcinoma cells.

In line with the previous studies, Dong et al. (2013) showed thatfructose 1,6-biphosphatase (FBP1)increases ROS production, and decreased the interaction 
between $\beta$-catenin and TCF, while increasing its interaction with FoxO. This then resulted in a suppression of basallike breast cancer (BLBC) stem cells and inhibited the tumour from enhancing. Furthermore, McClelland Descalzo et al. (2016) showed that glucose induces ROS production in embryonic stem cells and activation of FoxO transcription factor, which not only increases ROS scavenging through the increased expression of the antioxidant FoxO target genes, but also decreases the proliferation of the cells.

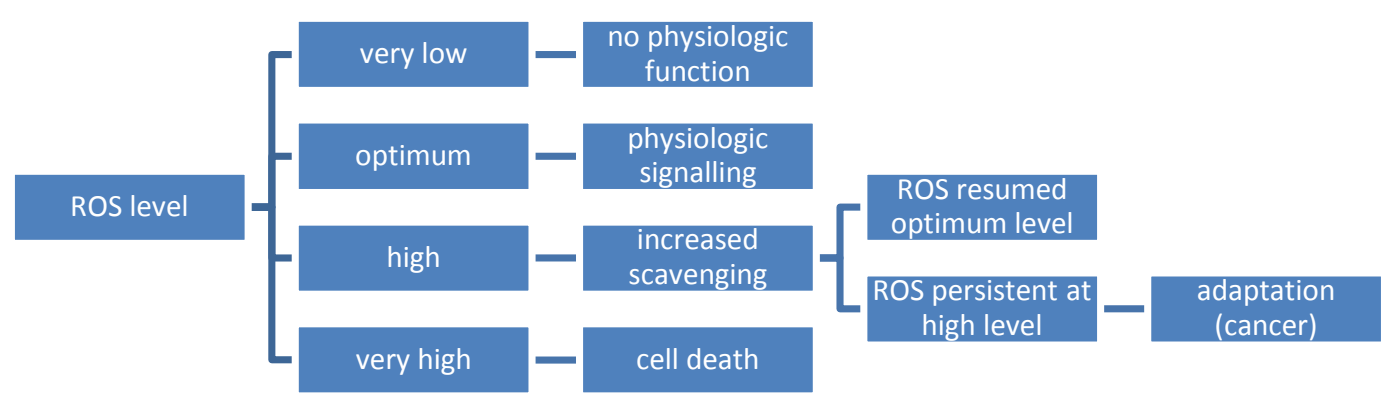

Figure 1: ROS level and possible outcomes

\section{CONCLUSION}

It has been established that ROS is needed as signalling molecules for physiologic functions. However, it is very crucial to maintain the ROS homeostasis (Figure 1). Levels that are below the physiologic threshold will impede physiological signalling, while levels that are above the threshold appears to manifest in three ways: activation of antioxidant genes (FoxO targets) that will result in increased ROS scavenging and resume of the balance; activation of antioxidant genes that could not resolve the issue but lead to the cellular adaptation to the high levels of ROS instead, a phenomenon observed in cancer cells; and activation of ROS-induced cell death. The Wnt/ $\beta$-catenin pathway seems to play an intricate role in maintaining this balance, through the effects of ROS on Dishevelled, GSK3 $\beta$, and $\beta$-catenin transcription complexes. Other than the type of cell and level of ROS itself, the duration of ROS exposure as well as the source of increased ROS seems to have effect on how the Wnt pathway is modulated in the presence of ROS. Much research is still needed to understand the complex interactions. 


\section{REFERENCES}

Almeida, M., Han, L., Martin-Millan, M., O'Brien, C. A., \& Manolagas, S. C. (2007). Oxidative stress antagonizes Wnt signaling in osteoblast precursors by diverting beta-catenin from $\mathrm{T}$ cell factor- to forkhead box O-mediated transcription. $J$ Biol Chem, 282(37), 27298-27305. doi:10.1074/jbc.M702811200

Antonenkov, V. D., Grunau, S., Ohlmeier, S., \& Hiltunen, J. K. (2010). Peroxisomes are oxidative organelles. Antioxid Redox Signal, 13(4), 525-537. doi:10.1089/ars.2009.2996

Bauer, G. (2012). Tumor cell-protective catalase as a novel target for rational therapeutic approaches based on specific intercellular ROS signaling. Anticancer Res, 32(7), 2599-2624.

Che, M., Wang, R., Li, X., Wang, H. Y., \& Zheng, X. F. (2016). Expanding roles of superoxide dismutases in cell regulation and cancer. Drug Discov Today, 21(1), 143-149. doi:10.1016/j.drudis.2015.10.001

Clements, W. M., Wang, J., Sarnaik, A., Kim, O. J., MacDonald, J., Fenoglio-Preiser, C., . . . Lowy, A. M. (2002). beta-Catenin mutation is a frequent cause of Wnt pathway activation in gastric cancer. Cancer Res, 62(12), 3503-3506.

Clevers, H. (2006). Wnt/beta-catenin signaling in development and disease. Cell, 127(3), 469-480. doi:10.1016/j.cell.2006.10.018

Dahmen, R. P., Koch, A., Denkhaus, D., Tonn, J. C., Sorensen, N., Berthold, F., . . Pietsch, T. (2001). Deletions of AXIN1, a component of the WNT/wingless pathway, in sporadic medulloblastomas. Cancer Res, 61(19), 7039-7043.

De Marco, P., Merello, E., Piatelli, G., Cama, A., Kibar, Z., \& Capra, V.
(2014). Planar cell polarity gene mutations contribute to the etiology of human neural tube defects in our population. Birth Defects Research Part A: Clinical and Molecular Teratology, 100(8), 633-641. doi:10.1002/bdra.23255

Dhar, S. K., \& St Clair, D. K. (2012). Manganese superoxide dismutase regulation and cancer. Free Radic Biol Med, 52(11-12), 2209-2222. doi:10.1016/j.freeradbiomed.2012. 03.009

Dong, C., Yuan, T., Wu, Y., Wang, Y., Fan, T. W., Miriyala, S., . . . Zhou, B. P. (2013). Loss of FBP1 by Snail-mediated repression provides metabolic advantages in basal-like breast cancer. Cancer Cell, 23(3), 316-331. doi:10.1016/j.ccr.2013.01.022

Essers, M. A., de Vries-Smits, L. M., Barker, N., Polderman, P. E., Burgering, B. M., \& Korswagen, H. C. (2005). Functional interaction between beta-catenin and FOXO in oxidative stress signaling. Science, 308(5725), 1181-1184. doi:10.1126/science.1109083

Funato, Y., Michiue, T., Asashima, M., \& Miki, H. (2006). The thioredoxinrelated redox-regulating protein nucleoredoxin inhibits Wnt-betacatenin signalling through dishevelled. Nat Cell Biol, 8(5), 501-508. doi:10.1038/ncb1405

Funato, Y., Terabayashi, T., Sakamoto, R., Okuzaki, D., Ichise, H., Nojima, H., . . Miki, H. (2010). Nucleoredoxin sustains Wnt/betacatenin signaling by retaining a pool of inactive dishevelled protein. Curr Biol, 20(21), 19451952. doi:10.1016/j.cub.2010.09.065

Hoogeboom, D., \& Burgering, B. M. (2009). Should I stay or should I go: beta-catenin decides under stress. Biochim Biophys Acta, 
1796(2),

63-74.

doi:10.1016/j.bbcan.2009.02.002

Hoogeboom, D., Essers, M. A., Polderman, P. E., Voets, E., Smits, L. M., \& Burgering, B. M. (2008). Interaction of FOXO with beta-catenin inhibits betacatenin/T cell factor activity. $J$ Biol Chem, 283(14), 9224-9230. doi:10.1074/jbc.M706638200

Kajla, S., Mondol, A. S., Nagasawa, A., Zhang, Y., Kato, M., Matsuno, K., . . . Kamata, T. (2012). A crucial role for Nox 1 in redoxdependent regulation of Wntbeta-catenin signaling. FASEB $J$, 26(5), 2049-2059. doi:10.1096/fj.11-196360

Katsuyama, M., Matsuno, K., \& YabeNishimura, C. (2012). Physiological roles of NOX/NADPH oxidase, the superoxide-generating enzyme. $J$ Clin Biochem Nutr, 50(1), 9-22. doi:10.3164/jcbn.11-06SR

Kikuchi, A., Yamamoto, H., Sato, A., \& Matsumoto, S. (2012). Wnt5a: its signalling, functions and implication in diseases. Acta Physiol (Oxf), 204(1), 17-33. doi:10.1111/j.1748-

1716.2011.02294.x

Kim, M. J., Kim, D. H., Na, H. K., \& Surh, Y. J. (2010). TNF-alpha induces expression of urokinasetype plasminogen activator and beta-catenin activation through generation of ROS in human breast epithelial cells. Biochem Pharmacol, 80(12), 2092-2100. doi:10.1016/j.bcp.2010.08.014

Lam, G. Y., Huang, J., \& Brumell, J. H. (2010). The many roles of NOX2 NADPH oxidase-derived ROS in immunity. Semin Immunopathol, 32(4), 415-430. doi:10.1007/s00281-010-0221-0

Latres, E., Chiaur, D. S., \& Pagano, M. (1999). The human F box protein
beta-Trcp associates with the Cul1/Skp1 complex and regulates the stability of beta-catenin. Oncogene, 18(4), 849-854. doi:10.1038/sj.onc.1202653

Lee, S., Kim, S. M., \& Lee, R. T. (2013). Thioredoxin and thioredoxin target proteins: from molecular mechanisms to functional significance. Antioxid Redox Signal, 18(10), 1165-1207. doi:10.1089/ars.2011.4322

Li, S., Esterberg, R., Lachance, V., Ren, D., Radde-Gallwitz, K., Chi, F., . . . Chen, P. (2011). Rack1 is required for Vangl2 membrane localization and planar cell polarity signaling while attenuating canonical Wnt activity. Proc Natl Acad Sci U S A, 108(6), 2264-2269. doi:10.1073/pnas.1013170108

MacDonald, B. T., Tamai, K., \& He, X. (2009). Wnt/beta-catenin signaling: components, mechanisms, and diseases. Dev Cell, 17(1), 9-26. doi:10.1016/j.devcel.2009.06.016

McClelland Descalzo, Darcie L., Satoorian, Tiffany S., Walker, Lauren M., Sparks, Nicole R. L., Pulyanina, Polina Y., \& zur Nieden, Nicole I. (2016). Glucose-Induced Oxidative Stress Reduces Proliferation in Embryonic Stem Cells via FOXO3A/ $\beta$-Catenin-Dependent Transcription of p21cip1. Stem Cell Reports, 7(1), 55-68. doi:http://dx.doi.org/10.1016/j.ste mcr.2016.06.006

Metcalfe, C., Mendoza-Topaz, C., Mieszczanek, J., \& Bienz, M. (2010). Stability elements in the LRP6 cytoplasmic tail confer efficient signalling upon DIXdependent polymerization. $J$ Cell Sci, 123(Pt 9), 1588-1599. doi: $10.1242 / j$ cs.067546 
Miller, R. K., \& McCrea, P. D. (2010).

Wnt to build a tube: Contributions of Wnt signaling to epithelial tubulogenesis. Developmental Dynamics, 239(1), 77-93. doi:10.1002/dvdy.22059

Moloney, J. N., \& Cotter, T. G. (2017). ROS signalling in the biology of cancer. Semin Cell Dev Biol. doi:10.1016/j.semcdb.2017.05.02 3

Nathan, C., \& Cunningham-Bussel, A. (2013). Beyond oxidative stress: an immunologist's guide to reactive oxygen species. Nat Rev Immunol, 13(5), 349-361. doi:10.1038/nri3423

Nishisho, I., Nakamura, Y., Miyoshi, Y., Miki, Y., Ando, H., Horii, A., . . . Hedge, P. (1991). Mutations of chromosome $5 \mathrm{q} 21$ genes in FAP and colorectal cancer patients. Science, 253(5020), 665-669.

Nusse, R., Brown, A., Papkoff, J., Scambler, P., Shackleford, G., McMahon, A., . . . Varmus, H. (1991). A new nomenclature for int-1 and related genes: the Wnt gene family. Cell, 64(2), 231.

Nusse, R., \& Clevers, H. (2017). Wnt/beta-Catenin Signaling, Disease, and Emerging Therapeutic Modalities. Cell, 169(6), 985-999. doi:10.1016/j.cell.2017.05.016

Nusse, R., \& Varmus, H. E. (1982). Many tumors induced by the mouse mammary tumor virus contain a provirus integrated in the same region of the host genome. Cell, 31(1), 99-109.

Pande, D., Negi, R., Karki, K., Khanna, S., Dwivedi, U. S., Khanna, R. S., \& Khanna, H. D. (2015). Oxidative Stress, Antioxidant Status, and Redox Signaling in Carcinogenesis. In V. Rani \& U. C. S. Yadav (Eds.), Free Radicals in Human Health and Disease (pp. 351-368). New Delhi: Springer India.

Pataki, C. A., Couchman, J. R., \& Brabek, J. (2015). Wnt Signaling Cascades and the Roles of Syndecan Proteoglycans. $J$ Histochem Cytochem, 63(7), 465480. doi:10.1369/0022155415586961

Pohl, S.-G., Brook, N., Agostino, M., Arfuso, F., Kumar, A. P., \& Dharmarajan, A. (2017). Wnt signaling in triple-negative breast cancer. Oncogenesis, 6(4), e310.

Prasad, B., Mah, D. J., Lewis, A. R., \& Plettner, E. (2013). Water oxidation by a cytochrome $\mathrm{p} 450$ : mechanism and function of the reaction. PLoS One, 8(4), e61897. doi:10.1371/journal.pone.006189 7

Qi, J., Lee, H. J., Saquet, A., Cheng, X. N., Shao, M., Zheng, J. J., \& Shi, D. L. (2017). Autoinhibition of Dishevelled protein regulated by its extreme $\mathrm{C}$ terminus plays a distinct role in $\mathrm{Wnt} /$ beta-catenin and Wnt/planar cell polarity (PCP) signaling pathways. $J$ Biol Chem, 292(14), 5898-5908. doi:10.1074/jbc.M116.772509

Reczek, C. R., \& Chandel, N. S. (2017). The Two Faces of Reactive Oxygen Species in Cancer.

Satoh, S., Daigo, Y., Furukawa, Y., Kato, T., Miwa, N., Nishiwaki, T., . . . Nakamura, Y. (2000). AXIN1 mutations in hepatocellular carcinomas, and growth suppression in cancer cells by virus-mediated transfer of AXIN1. Nat Genet, 24(3), 245250. doi:10.1038/73448

Scheit, K., \& Bauer, G. (2015). Direct and indirect inactivation of tumor cell protective catalase by salicylic acid and anthocyanidins reactivates intercellular ROS 
signaling and allows for synergistic effects. Carcinogenesis, 36(3), 400-411. doi:10.1093/carcin/bgv010

Segditsas, S., \& Tomlinson, I. (2006). Colorectal cancer and genetic alterations in the Wnt pathway. Oncogene, 25(57), 7531-7537. doi:10.1038/sj.onc.1210059

Serrano, M., \& Blasco, M. A. (2007). Cancer and ageing: convergent and divergent mechanisms. Nat Rev Mol Cell Biol, 8(9), 715-722.

Shin, S. Y., Chin, B. R., Lee, Y. H., \& Kim, J. H. (2006). Involvement of glycogen synthase kinase3beta in hydrogen peroxideinduced suppression of Tcf/Lefdependent transcriptional activity. Cell Signal, 18(5), 601-607. doi:10.1016/j.cellsig.2005.06.001

Shin, S. Y., Kim, C. G., Jho, E. H., Rho, M. S., Kim, Y. S., Kim, Y. H., \& Lee, Y. H. (2004). Hydrogen peroxide negatively modulates Wnt signaling through downregulation of beta-catenin.
Cancer Lett, 212(2), 225-231. doi:10.1016/j.canlet.2004.03.003

Wang, Y. (2009). Wnt/Planar cell polarity signaling: a new paradigm for cancer therapy. Mol Cancer Ther, $8(8)$, 2103-2109. doi:10.1158/1535-7163.MCT-090282

Zanardelli, S., Christodoulou, N., \& Skourides, P. A. (2013). Calpain2 protease: A new member of the $\mathrm{Wnt} / \mathrm{Ca}(2+)$ pathway modulating convergent extension movements in Xenopus. Dev Biol, 384(1), 83100. doi:10.1016/j.ydbio.2013.09.017

Zhan, T., Rindtorff, N., \& Boutros, M. (2017). Wnt signaling in cancer. Oncogene, 36(11), 1461-1473. doi:10.1038/onc.2016.304

Zhou, D., Shao, L., \& Spitz, D. R. (2014). Reactive oxygen species in normal and tumor stem cells. $A d v$ Cancer Res, 122, 1-67. doi:10.1016/B978-0-12-4201170.00001-3 